\title{
An Unlikely Source of (Absurd and Effective) Case Studies for Introductory Informal Logic
}

\author{
KAMIL LEMANEK \\ Department of Philosophy \\ University of Warsaw \\ Krakowskie Przedmieście 3, 00-927, Warszawa \\ Poland \\ K.Lemanek@uw.edu.pl
}

\begin{abstract}
This short work presents a popular fringe theory as a source of case studies for use in teaching informal logic in an introductory course. It puts forward ancient astronaut theory as the candidate source, together with a characterization of why it fits the bill. The televised material associated with that theory is well suited to being used as case studies given that they are easy to follow, contain a surprising number of arguments and fallacies, and keep students reliably engaged. The paper includes an overview of the forms of argumentation and fallacies that these cases may be used to teach, along with a sketch of how to best implement them in the classroom.
\end{abstract}

Résumé: Ce court ouvrage présente une théorie marginale populaire comme source d'études de cas à utiliser dans l'enseignement d'un cours introductoire de la logique non formelle. Il suggère la discussion de la Théorie d'astronaute antique et décrit comment son utilisation répond à divers objectifs pédagogiques. Le matériel télévisé associé à cette théorie convient bien en tant que cas faciles à suivre et contient un nombre surprenant d'arguments et d'erreurs qui font participer les étudiants de manière fiable. Cet article comprend un aperçu des formes d'argumentation et des erreurs que ces cas peuvent illustrer dans l'enseignement de la logique non formelle, ainsi qu'une esquisse de la meilleure façon d'employer ce matériel en classe.

Keywords: education; pedagogy; case study; critical thinking; fallacy; aliens

\section{Introduction}

The case study method of teaching in higher education is an interesting and effective approach that focuses on scenarios and material as a means of engaging students and drawing them into the learning process (Boehrer and Linsky 1990; Kreber 2001; Herreid 
2011). Cases are generally understood to present some sort of story, the function of which is to produce "a rich and lively discussion of the issues that the teacher wants the students to confront" (Boehrer and Linsky 1990, p. 45). This approach has naturally found success in the informal logic classroom, as noted by Douglas Walton (2000) in describing his own experience: "My technique is to build everything around the case study method. The classes begin with an exposition of general methods, but quickly turns to individual case studies of examples of argumentative discourse. I use examples from magazines, newspapers, news media, parliamentary debates, and all kinds of other sources" ( $p$. 36). ${ }^{1}$ The approach is a good way of moving through material while keeping students' attention, illustrating important nuances, and at the same time providing a format that can easily be transposed to assignments and the like. However, as Walton pointed out, focusing on case studies does not work particularly well for introductory students. Many of them have difficulties with basic concepts, and the introduction of real-world material with all of its subtleties can very easily lead to confusion, frustration, and ultimately disengagement. Unfortunately, the more appropriate, simpler mechanical examples found in textbooks often tend to either bore students or otherwise quickly lose their attention, despite our best efforts to keep them interested and participating. The traditional method has personally worked well enough all in all, but over the past few years, I have been searching for and experimenting with material that could serve as the basis of simple case studies for these introductory classes - in particular, for fallacies.

My search has led me to an unexpected source of effective and approachable case study material: ancient astronaut theory (AAT). It is a wild theory that basically holds that extra-terrestrials interacted with ancient civilizations and affected the course of human development. The televised material associated with that idea is rife with questionable argumentation and transparent fallacies, which is the perfect basis for engaging case studies that can be

\footnotetext{
${ }^{1}$ Of course, Walton elaborated a more technical understanding of case studies and their place in argumentation (e.g., Walton 1993; cf. 1984). I will be using the term in the more general pedagogic sense indicated above, following Boehrer, and Linsky (1990) and Herreid (2011).
} 
used as supplements for units on argumentation designed with introductory students in mind. Although the proposal is fairly modest, in that it does not apply to a course as a whole, I believe it has practical educational value. The considerations it outlines and the schematic it provides may be used on a smaller scale to good effect; with appropriate material in hand, it provides an engaging, entertaining, and educationally viable option for introductory courses.

The structure of this work is as follows: In section two, I outline what makes AAT so well suited to the informal logic classroom-I also discuss the preferred, multi-media format. In section three, I explain what it can be used to teach, including a general characterization of the material and a set of specific fallacies and forms of argumentation commonly encountered in it. I also provide a sample transcript along with some commentary at the end of the section. In section four, I outline how I believe this material is best implemented: when and how to use it.

\section{Characterizing the material}

What makes AAT so interesting from an educational standpoint in the context of informal logic is a combination of factors including that it is a fringe theory, featuring a broad narrative, and that it is popular. I will explain the importance of each in turn.

\section{Fringe theory}

It goes without saying that AAT is a fringe theory; that is, it is a view that has no serious academic support. It relies on a variety of speculative arguments to make its case rather than hard evidence. While it often calls upon scientific claims, it never aims to compete with scientific method or conventional science as such, which distinguishes it from standard pseudoscientific theories (see Hansson 2013; Derksen 1993). Because the argumentation does not necessarily come down to mistaken empirical claims, they leave space for discussion with respect to the argumentation itself and our intuitions. Moreover, it makes few appeals to plots and disinformation, tactics characteristic of conspiracy theories (see Keeley 1999; Räikkä 2014). Which means that AAT does not neces- 
sarily reject contradicting evidence and potential counterarguments in the way that conspiracy theorists might. It balances between the cut and dry empirical shortcomings of pseudoscience and the argumentatively deflating, though psychologically interesting, tendency of conspiracy theories to remain selectively insensitive to evidence and reason.

To be sure, AAT is a fringe theory for a reason: the arguments it presents, and its claims, suffer from a myriad of shortcomings, many of which are very clear. But for the purposes of teaching, those shortcomings serve as examples for the students to learn from. The fact that many of them are painfully obvious (from our perspective) is particularly helpful for introductory students who are just coming to grips with some of these techniques and mistakes.

\section{Broad narrative}

The idea that aliens significantly interacted with human beings in the distant past is spun into a variety of different explanations. Its proponents have angled to explain feats of architecture, our genetics, our technology, our religions, etc. on the basis of the core claim. In constructing these explanations, they cite evidence, recall arguments, and often turn to speculating about why certain events took place, whether in terms of the motivations of ancient civilizations or the aims of mysterious extra-terrestrials. Each explanation is its own little case - a story-like account of a phenomenon that presents the world in a certain light. That narrative element, which is paradigmatic of good cases, plays a role in keeping the students interested, but it also plays a more notable theoretical role with respect to informal logic: a story can easily support a more elaborate structure featuring a number of distinct arguments and rhetorical moves, facilitating a kind of natural complexity. Of course, that is not necessarily a good thing, but it has its value when used appropriately, for instance, illustrating how arguments interact with one another or how basic mistakes may be compounded. It has more to 
offer than a simple example argument or a one-off claim lacking any clear context.

\section{Popular}

Although there are many fringe theories, few of them are as popular as AAT (as oxymoronic as a "popular fringe theory" might sound). There are two things to consider here. First, popularity leads to the production of material. There are books, blogs, documentaries, and television shows packed with this kind of content - in fact, there are fifteen seasons (and counting, believe it or not) of a television show entitled Ancient Aliens that presents AAT to mass audiences. That popularity has its own purely practical value: material is easy to find, and there is plenty of it to choose from. Second, the material itself is popular in part because it is easy to follow. The ideas they contain are approachable and fairly coherent, which is, again, something that proves valuable for introductory students.

As an educational tool, AAT has proven most effective, in my experience, when used as a source of case studies drawn from the television show, Ancient Aliens, noted above, and that will be the focus of what follows. The format itself comes with a number of inherent strengths. First, audio-visual examples tend to keep students' attention (see, e.g., Berk 2009), and the unintentionally amusingly dramatic visuals and score used in the episodes certainly help with that. Second, the episodes are thematic and selfcontained, in that each one explores one specific topic (e.g., architecture, religion), and they don't rely on arguments from other episodes, which is to say that any given episode can be used without having to worry about clarifying background. Third, each episode is designed with commercial breaks and mass audiences in mind, which means that the episodes are broken into manageable segments with natural stopping points. I will consider the value of the first point to be self-evident, whereas the following two play a role in how this material is implemented in practice, as described in section three.

In addition to the upsides of the format, it needs to be said that the subject-matter itself inspires quite a bit of engagement among 
students. The fact that this is authentic material found in the real world (broadcast to millions of people), as opposed to being a set of artificial examples from a textbook, certainly makes an impression. It is also an outrageous theory, which students tend to pick up on immediately. The aim of the arguments, the way they are put forward, and the dramatic claims are all a bit comical. And one of the less obvious advantages of using such a bizarre topic is that nobody finds it offensive when its sheer absurdity starts to dawn on the class (cf. Sullivan 2018). Even if a student were sympathetic to AAT for whatever reason, it simply does not have the weight or seriousness of political or religious beliefs. A wild theory and a bit of neutral humor can go a long way when it comes to student engagement. $^{2}$

The overview and transcript in the next section specify what these episodes can be used to teach, and they also give a sense of what is on offer here more generally. That being said, it should be kept in mind that the transcription obviously does not do justice to the two points noted above: the audio-visual format and the amusing qualities of the material.

\section{What it can teach}

In order to get an idea of what can be taught using AAT and Ancient Aliens, we should start with its most general tendency: more often than not, a given episode will attempt to sketch something as some sort of mystery. They then produce evidence and arguments that suggest that AAT is the solution to the mystery, and the conclusion is usually delivered in the form of an over-arching inference to best explanation. That formula is usually reproduced on a

\footnotetext{
${ }^{2}$ It may be worth noting that I have glossed over the question of whether this material aligns with other paradigmatic case study criteria like producing scenarios that resist straightforward resolution or that have two supportable sides (Herreid 2007, ch. 7; Bennett and Chakravarthy 1978). I have done so for the sake of brevity. While the material could very well be construed to match that criteria with some theoretical exposition, I feel that it would not be particularly productive. This is especially so given that the case study method is open to a wide range of variations, where that criteria may vary or be altogether absent (see, e.g., Herreid 2011; one such formulation: Gross Davis 2009, ch. 24).
} 
smaller scale within the segments of the episode, and the supporting evidence and argumentation takes a variety of forms. I have singled out three of the most common admissible forms of reasoning found in the episodes, together with a concise explanation of how they tend to be misused or compromised therein. I have also provided a list of the most commonly encountered fallacies and named two notable absences.

The inferences to best explanation that appear in the episodes are often explicitly faulty, stating that there could not be any other possible explanation than alien involvement despite not actually eliminating any other possibility. Given that there are obviously other more plausible explanations in just about every case, these conclusions provide straightforward examples of how inferences to best explanation can be masked or misused in situ.

Inductive generalizations are produced to serve as support for more central claims, often generalizing over different ancient civilizations and phenomena like religion, architecture, and development. However, these generalizations are often faulty. Their shortcomings range from rather subtle issues with vagueness to spectacular, overstated generalizations that are clearly untenable. They also raise questions concerning consistency in terms of how one draws generalizations.

Varieties of appeals to authority are made as well-for example, episodes often include commentary from experts in academia concerning their own fields (e.g., physicists, bio-chemists, information engineers, etc.). They tend to provide general claims that are then mixed into the broader point being made in the episode. However, many of the crucial claims are delivered by figures with apparently little relevant expertise, introduced as radio hosts, magazine editors, and "authors." Similarly, figures like Plato are called upon as the basis of certain claims or to initiate and anchor a line of reasoning (e.g., concerning Atlantis, not his philosophy). The way they are presented as authorities raises a host of concerns.

The fallacies that are most frequently encountered include, in no particular order, begging the question, strawman arguments, argument from ignorance (argumentum ad ignoratiam), fallacy of composition (and division), fallacy of irrelevant conclusion (ignoratio elenchi), fallacy of false equivalence, and fallacy of equivo- 
cation. Among the notable absences, there are few examples of strictly probabilistic fallacies, and though there are occasional arguments that can be likened to conceptual slippery slopes, I have not found any that are particularly clear.

To illustrate just how this all fits into a given episode of Ancient Aliens, I have prepared a short transcription from roughly five minutes of an episode (season 12, episode 4, 11:28). I have also included some commentary to the left of the transcript to indicate where fallacies and potential talking points come up. I would recommend reading it in sections, starting with the transcript and then the commentary.

\section{There are some perfectly fair points here. Interesting credentials for the expert.}

An episode concerning megalithic stone structures on earth and

"The Alien Architects"
the idea that aliens masterminded their construction.

This is a strawman, who says

Rhetorical force, but no real issue here.

Narrator: Even more confounding is the fact that many of these megalithic constructions were built in impractical locations, often thousands of feet above sea level.

Narrator: Santorini, Greece.

Narrator: Researcher and editor Giorgio Tsoukalos (TK) travelled to the ancient site of Thira on the island's highest peak. The megalithic architecture found here dates back to at least the $9^{\text {th }}$ century BC. TK: This wall exists here, at one of the most inaccessible places. In order to get here, you take a car, you go up these harrowing switchback roads, and then you're on foot for at least 45 minutes. And so, the idea that is given that this was just built on a whim, to me, just seems insane. There had to have been a reason why this is here. The blocks are huge ... [some description of the size of the stones, which are indeed large].

Describing the wall at Thira:

TK: And we have twelve levels of stone blocks, twelve!

Indicating an irregularly shaped stone:

TK: This was place here deliberately. Deliberately! This is not a coincidence. Some- 
A peculiar, fallacious move from the existence of similar structures to their having an identical building style. At bottom, fallacy of false equivalence.

Acceptable, though a potentially loaded question and a bit of hyperbole.

Mistaken generalization, making a leap from Incan architecture to all

"ancient" stone architecture.

Hasty generalization. one at the quarry said, "We need a stone of this particular size that fits right here."

TK: And walls like this exist not only in Greece, and in Italy, and in Spain [Images of stone walls are shown side by side; they do not look particularly similar], and in South America, and also in Egypt [Images of stone walls are again shown side by side; these look altogether different from the European examples].

TK: So, the building style is not similar, it is identical.

\section{Scene transition}

Narrator: The use of such enormous blocks is the main reason why many of these ancient structures, like the walls at Thira, have survived until today. But why was it so important that they remain standing, thousands of years into the future?

Freddy Silva (author, FS): There was an architect here who had complete understanding of stone, of masonry, and that you can do extraordinary things with it that will last a lifetime and forever. [Images of Incan architecture are being shown]

FS: Not only did they build things which were guaranteed to last, often they were working with unusual angles, and they're so tightly fitted that earthquakes find them difficult to break apart, in fact they are earthquake-proof. [Continued stream of images of Incan architecture.]

Scene transition

Narrator: [Images of altogether different ancient architecture] Ancient astronaut theorists point out that other common design elements were incorporated in structures throughout the world to ensure their longevity.

Followed by a series of claims and arguments concerning the longevity of stone structures, including the use metal braces (omitted for the sake of brevity). 
A wild claim that seems to be an inference to best explanation

TK: Who were the teachers of these engineering styles? The only conclusion there is is that aliens had a hand in these creations a long time ago. They're all human made, but with the assistance or the technology provided by extra-terrestrials.

\section{Scene transition}

What I hope comes across here is just how much could be said about a clip that is so short. There are quick and hard to notice fragments like the strawman that pop up out of nowhere, very clear and obvious improprieties in the cases of the other noted fallacies, and some subtleties to discuss in terms of some of the purely rhetorical material and the matter of loaded questions and hyperbole. It is rich in content, with varying degrees of difficulty (though nothing too tough) and topics for open discussion.

\section{Implementation}

I have found most success using AAT and Ancient Aliens in the form of supplemental case studies. Putting it schematically, I use them two to three times in the course of a semester. The first of these takes place after we have gone through the core inductive concepts and basic forms of related argumentation, like inference to best explanation and argument from analogy. As such, the students are already familiar with the basic issues surrounding generalizations and the like. Each of the classes featuring an episode begins with a standard presentation of a selected set of fallacies, together with examples and simple exercises.

The set of fallacies is chosen together with an episode that features them (or examples that are near misses). There are not any specific criteria that limit one's choice of episode aside from what types of arguments and mistakes appear in them. As noted earlier, the episodes are self-contained and do not require additional context from other episodes. Moreover, every individual episode is devoted to a well-defined and focused topic, making each one a miniature case.

The material needs to be broken into parts to make discussing it possible. I prepare two segments within a given episode. Segments range from five to ten minutes and they pair with the natural 
breaks in the program. Within those segments, I introduce one or two further breaks. I try to fit them in between arguments or scenes. With those preliminaries in order, we can move to how the exercise ought to be conducted.

The format is explained to the students: I ask them to pay attention as they watch and to jot down or remember issues as they see them come up. I tell them to expect a pause every few minutes. I then play the first minute of the chosen episode, which outlines the aim of that particular episode - it sets up the case. From there I move to the first segment. At each pause, I ask the students to volunteer what issues they might have seen or whether everything looked in order. I often ask for further elaboration and encourage contributions from others. The aim is to get the students responding to the material but also responding to each other, either questioning the points made by other students or building upon them (and defending their points if need be). My role is to mediate the discussion, which involves making minor comments and choosing who speaks next if necessary.

In mediating, I also manage the target of discussion and the time. Managing the target of discussion is a matter of guiding the students to the right issues. If no one volunteers or begins expanding upon a particular issue, I ask the class for input with a probing question. If no response is forthcoming, I begin sketching the problem myself, and then invite contributions from the students to round it out. Managing the time is a matter of making sure the discussion moves along quickly enough to cover the planned topics and points of interest.

The whole exercise puts the fallacies into a real-time environment, and student participation has never been a problem. The nature of the material and the short bursts of content keep their attention, prompt responses, and keep the discussion manageable. Importantly, the students that do not participate directly still appear to be engaged, in that they listen and react to the discussion and the episode. In the student surveys that are routinely performed at the end of the semester, the majority of the students report these case studies as their favorite part of the class in the open answer section of the survey, which certainly supports the impression. 


\section{Conclusion}

As challenging as it may sometimes be to teach introductory students, creative sources like the one described above can make a difference. Of course, finding an interesting source is one thing, finding a useful source is another, and actually figuring out how to effectively implement it as a case study is another still. What I have presented above is an exceptionally interesting source, and one that has proven exceptionally useful as a teaching aid. That is not to say that this type of introductory level, multi-media case study format could not be reproduced using an altogether different material, but I do believe that ancient astronaut theory and Ancient Aliens happen to be very well suited to that role. With appropriate material like this in hand, I believe the case study method is worth implementing. It provides an engaging, entertaining, and educationally viable option for introductory courses focusing on argumentation.

\section{References}

Bennett, J. B. and B. Chakravarthy (1978). What awakens student interest in a case? Harvard Business School Bulletin 54(2): $12-15$.

Berk, R. A. (2009). Multimedia teaching with video clips: TV, movies, YouTube, and mtvU in the college classroom. International Journal of Technology in Teaching and Learning 5(1): 1-21.

Boehrer, J. and M. Linksy (1990). Teaching with cases: Learning to question. New Directions for Teaching and Learning 42: 41-57.

Derksen, A. A. (1993). The seven sins of pseudoscience. Journal for General Philosophy of Science 24: 17-42.

Gross Davis, B. (2009). Tools for teaching. San Francisco, CA: Jossey-Bass.

Hansson, S. (2013). Defining pseudoscience and science. In Philosophy of pseudoscience: Reconsidering the demarcation problem, eds. Massimo Pigliucci and Maarten Boudry, 6179. Chicago, IL: University of Chicago Press. 
Herreid, C. F. (2007) What makes a good case? In Start with a story: The case method of teaching college science, 45-48. Arlington, VA: NSTA Press.

(2011). Case study teaching. New Directions for Teaching and Learning 128: 31-40.

Keeley, B. (1999). Of conspiracy theories. The Journal of Philosophy 96(3): 109-126.

Kreber, C. (2001). Learning experientially through case studies? A Conceptual Analysis. Teaching in Higher Education 6(2): 217-228.

Räikkä, J. (2014). On the epistemic acceptability of conspiracy theories. In Social Justice in Practice: Studies in Applied Philosophy, Epistemology and Rational Ethics, vol. 14, 6175. Berlin, Germany: Springer.

Sullivan, S. (2018). Donald Trump as a critical-thinking teaching assistant. Informal Logic 38(1): 118-132.

Walton, D. (1984) Logical dialogue-games and fallacies. Lanham, MA: University Press of America.

(1993) The normative structure of case study argumentation. Metaphilosophy 24(3): 207-226. (2000). Problems and useful techniques: My experiences

in teaching courses in argumentation, informal log 